\title{
Breast Arterial Calcifications on Mammography among Patients Attending the Radiology Department in a Tertiary Care Centre: A Descriptive Cross-sectional Study
}

\author{
Anamika Jha, 'Anugya Sah, 'Birendra Raj Joshi, 'Benu Lohani' \\ 'Department of Radiology, Tribhuvan University Teaching Hospital, Maharajgunj Medical Campus, Maharajgunj,
} Kathmandu, Nepal.

\begin{abstract}
Introduction: Breast arterial calcifications are common mammographic findings which are associated with coronary artery disease. The aim of this study was to find the prevalence of breast arterial calcifications in women presenting for mammography in a tertiary care centre.

Methods: This descriptive cross-sectional study was performed in the Department of Radiology, in a tertiary care hospital after taking ethical clearance, Reference number 352(6-11)E-2, 077/078, data was collected from Syngovia database from March-June 2021 which included 1614 mammograms. Convenience sampling was done and mammograms evaluated for presence of vascular or nonvascular calcification. Further, vascular calcification was graded. Data was entered in Statistical Package for Social Sciences version 25. Point estimate at 95\% Confidence Interval was done, and frequency and proportion were calculated.
\end{abstract}

Results: The prevalence of breast arterial calcification was 188 (11.6\%) at 95\% Confidence Interval (10.03-13.2). The mean age of women included in this study was $48.42 \pm 9.55$ years with the largest number of patients in the age group $40-49$ years, $682(42.3 \%)$, and least in the age group 80-89 years, $3(0.2 \%)$. All patients in the age group $80-89$ years, $3(100 \%)$ had vascular calcifications followed by $70-79$ years group, $22(57.5 \%)$ and none in patients younger than 30 years.

Conclusions: We found an increase in the number and grade of vascular calcifications in breasts with the patient's age. When present breast arterial calcifications must be mentioned in mammogram report. Identification of such calcifications on mammogram should prompt further screening for atherosclerotic disease.

Keywords: atherosclerosis; calcification; mammography.

\section{INTRODUCTION}

Mammograms are commonly done for screening of breast cancer or evaluation of breast symptoms. In Nepal, diagnostic mammograms are done more often than screening due to lack of awareness and absence of guidelines facilitating screening studies. ${ }^{1}$ Breast arterial calcifications (BAC) represent arteriosclerotic changes occurring in medium sized arteries supplying the breast.

Different calcifications, including vascular, are often seen in mammograms, but being unrelated to breast disease, are often not reported. Various studies have shown an increased risk of Coronary Artery Disease (CAD) with BAC. ${ }^{2-4}$ In addition to $C A D$, other risk factors like age, Diabetes Mellitus, CAD risk factors, pregnancy, lactation and renal impairment are also associated with BAC. ${ }^{5}$ Reporting BAC may help identify group of patients at higher risk of CAD and prompt appropriate and timely evaluation.

The aim of our study was to find the prevalence of BAC in women presenting for mammography in our tertiary care hospital.

Correspondence: Dr. Birendra Raj Joshi, Tribhuvan University Teaching Hospital, Maharajgunj Medical Campus, Maharajgunj, Kathmandu, Nepal. Email: swasulav@gmail. com, Phone: +977-9841701333 


\section{METHODS}

This was a descriptive cross-sectional study conducted in the Department of Radiology, Tribhuvan University Teaching Hospital (TUTH). Data was collected from the database over a period of 4 months (March-June 2021). Ethical clearance [Reference number 352(611)E-2, 077/078] was obtained from the Institutional Review Committee and patient confidentiality was maintained. Convenient sampling technique was used. Patients with breast implants or previous breast surgery deforming the breast, rendering evaluation difficult were excluded.

The sample size was calculated using the formula,

$$
\begin{aligned}
\mathrm{n} & =\mathrm{Z}^{2} \times \mathrm{p} \times \mathrm{q} / \mathrm{e}^{2} \\
& =(1.96)^{2} \times 0.5 \times 0.5 /(0.03)^{2} \\
& =1,067
\end{aligned}
$$

where,

$\mathrm{n}=$ required sample size

$\mathrm{p}=$ prevalence $50 \%$

$q=1-p$

$\mathrm{e}=$ margin of error, $3 \%$

$\mathrm{Z}=1.96$ at $95 \%$ Confidence Interval $(\mathrm{CI})$

Adding a non-response rate of $10 \%$, the sample size was 1,174 . However, 1614 samples were included in the study.

Two basic projections (cranio-caudal \& mediolateral oblique) of the breasts were obtained with the MAMMOMAT Fusion mammographic unit. These mammograms available in Syngovia work station YLXRO19095 database were evaluated by radiologists with more than 10 years of expertise. The pattern and extent of calcification was evaluated visually in the workstation using appropriate magnification tools. Presence of calcification of any type was noted and classified as benign vascular, benign non-vascular or malignant. Vascular calcification was further graded as follows, which was adapted from the previously proposed scoring systems. ${ }^{6,7}$

0 . No vascular calcification;

1. Few punctate vascular calcifications with no coarse, tram track or ring calcifications;

2. Abundant punctate vascular calcification or tram track calcifications;

3. Severe coarse or tram track calcification obliterating or clouding the lumen.

Study variables were recorded in a predesigned datasheet. Statistical analyses were done with the SPSS version 25.0 and Microsoft Excel. Simple statistical measures were used to determine the overall prevalence and grade of calcification and that in the different age groups.

This study was done as a part of the University Grant Commission project FRG-HS-3 075-76.

\section{RESULTS}

The prevalence of BAC in our study was found to be $188(11.6 \%)$ at $95 \% \mathrm{Cl}(10.03-13.2)$.

The study sample consisted of 1614 female patients with age ranging from 20 to 89 years, mean age of $48.42 \pm 9.55$ years. The maximum number of patients were in 40-49 years, $682(42.3 \%)$ age group and minimum in $80-89$ years, $3(0.2 \%)$ (Table 1, Figure 1$)$.

Table 1. Distribution of different types of calcifications in various age groups.

\begin{tabular}{|llllll|}
\hline Age group & $\begin{array}{l}\text { Calcification } \\
\text { Absent }\end{array}$ & Benign Vascular & Benign non-vascular & Malignant & $\begin{array}{l}\text { Total number in various } \\
\text { age groups. }\end{array}$ \\
$20-29$ & $21(1.3)$ & $0(0)$ & $1(0.06)$ & $0(0)$ & $22(1.4)$ \\
$30-39$ & $171(10.5)$ & $7(4.3)$ & $27(1.7)$ & $8(0.5)$ & $213(13.2)$ \\
$40-49$ & $524(32.4)$ & $29(1.8)$ & $118(7.3)$ & $11(6.8)$ & $682(42.3)$ \\
$50-59$ & $293(18.1)$ & $57(3.5)$ & $112(6.9)$ & $7(0.4)$ & $469(29.1)$ \\
$60-69$ & $74(4.5)$ & $70(4.3)$ & $39(2.4)$ & $2(0.1)$ & $185(11.5)$ \\
$70-79$ & $9(0.5)$ & $22(1.4)$ & $8(0.5)$ & $1(0.06)$ & $40(2.5)$ \\
$80-89$ & $0(0)$ & $3(0.2)$ & $0(0)$ & $0(0)$ & $3(0.2)$ \\
Total & $1092(67.6)$ & $188(11.6)$ & $305(18.8)$ & $29(1.8)$ & 1614 \\
\hline
\end{tabular}

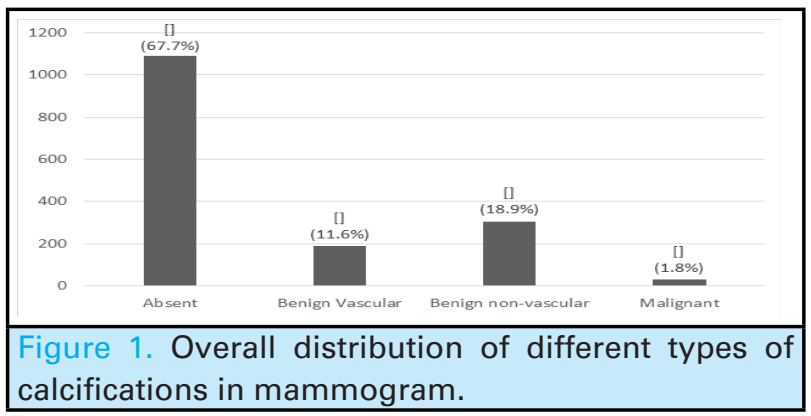

The mean age of patients without vascular calcification was $46.32 \pm 8.38$ and that with vascular calcification was $58.13 \pm 10.27$ years. A total of $22(1.4 \%)$ women in the age group $20-29$ years and $213(13.2 \%)$ women in the age group 30-39 years in our study were below the recommended age for mammography, which is suggested for women above the age of 40 . However, these women had risk factors like personal or family history of breast cancer, or had undergone diagnostic mammography. 
Calcifications were seen in a total of $522(32.3 \%)$ mammograms of which $188(36 \%)$ were benign vascular, $305(58.4 \%)$ were benign non vascular and 29 (5.5\%) malignant (Figure 2 and Table 1). The prevalence of BAC in our study was 188 (11.6\%) with a maximum number in the 60-69 years age group. There were $121(7.5 \%)$ cases with grade 1, 48 (3\%) with grade 2 and $19(1.2 \%)$ with grade 3 calcification. Maximum percentage of grade 1 calcification was in 50-59, grade 2 in 60-69 and grade 3 in 80-89 years age groups (Figure 2).

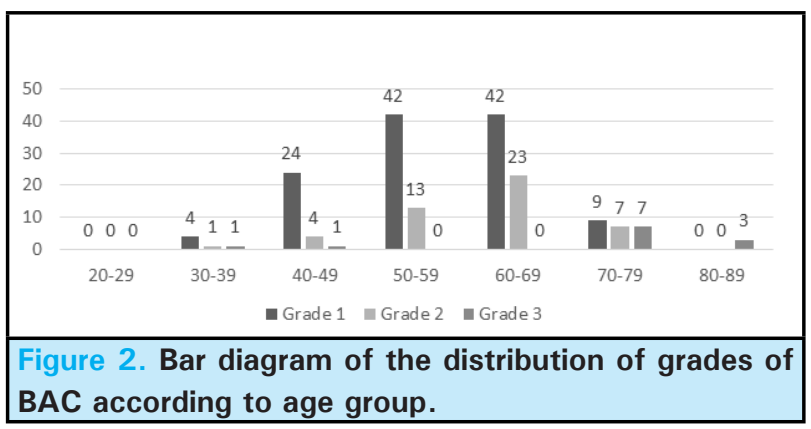

There was an increase in prevalence of BAC with increasing age, with no calcifications in less than 29 years of age and all patients older than 80 years having BAC (Figure 3).We found increase in the number and grade of BAC with age.

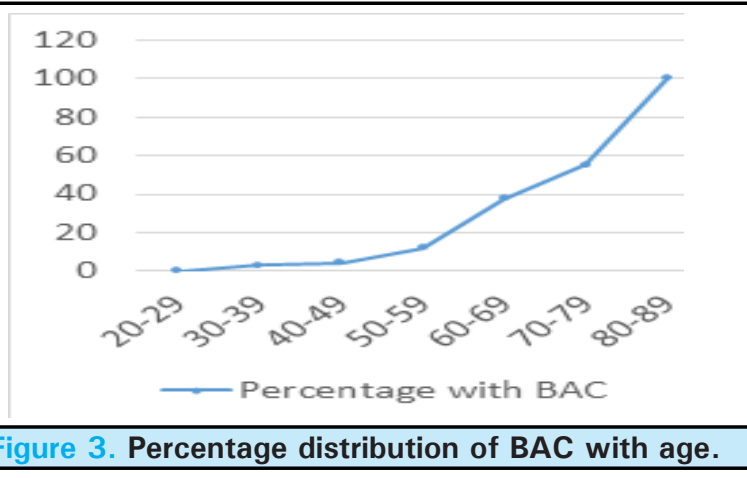

\section{DISCUSSION}

BAC more often involves calcification in the tunica media and represents arteriosclerosis than atherosclerotic intimal calcification. These are fine initially, becoming a more definite linear or tram track followed by dense, coarse and confluent obscuring the vessel lumen. ${ }^{8}$ It may be difficult to differentiate medial or intimal calcification on mammogram. Studies have shown a higher incidence of BAC in patients with renal disease, atherosclerotic coronary artery disease, CAD risk factors, diabetes as well as previous

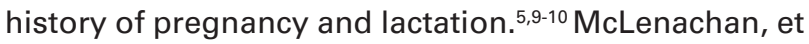
al. concluded that while absence of BAC has a high negative predictive value for ruling out CAD, the diagnostic accuracy to predict the same is limited. ${ }^{11}$ Some other studies do not show any association between BAC and CAD.

We had more patients with grade 1 calcification than grade 2 or 3 and an increasing number and grade of BAC with age, with all those above 80 years of age having grade 3 BAC. The increase in presence and grade of BAC with age in our study is consistent with most other studies.

The prevalence of breast calcifications in our study of any type, that is, vascular or non-vascular was about $522(32.3 \%)$ and BAC was 188 (11.6\%). Studies have shown the prevalence of BAC generally varies from $9-17 \%$, being higher in older patients. ${ }^{3} A$ similar study which had population ranging from $49-70$ years, showed prevalence similar to our study of $11 \%$, and found a positive association with age, pregnancy and lactation. However, they did not find any relation between BAC and atherosclerotic risk factors. ${ }^{12}$ The prevalence of BAC was $14.1 \%$ in another study, including patients from 40-93 years of age, with increasing trend with age. ${ }^{2}$ Higher prevalence of $20 \%$ was seen in a study conducted in Nigeria. ${ }^{3}$ Reddy $\mathrm{J}$, et al. found the overall prevalence of BAC to be $29.4 \%$ in patients from $35-92$ years of age, which varied with ethnicity, being $34.5 \%$ in Hispanics, $24 \%$ in whites and $7.1 \%$ for Asians. ${ }^{13}$ Compared to our study, while most others have greater BAC prevalence, some show a lower prevalence, minimum being $3 \%$. The slightly lower prevalence in our study could be due to a greater number of younger patients with diagnostic indications more often than screening mammograms. ${ }^{1}$ We had a few patients younger than 40 years, who either had high risk factors for breast carcinoma or another diagnostic indication.

While such vascular calcifications are often seen on mammography, being unrelated to breast cancer, they are not always mentioned in the report. An interesting study found that patients and preventive cardiologists prefer BAC being reported in mammogram studies done for other indications. ${ }^{14}$ It is important to make a note on this incidental finding. ${ }^{15}$

\section{CONCLUSIONS}

Since there is an increase in prevalence and grade of vascular calcification with age. We recommend that the benign vascular calcification when present must always be reported in the mammogram report, as such patients may have higher risk of atherosclerotic disease.

Conflict of Interest: This study was done as a part of the University Grant Commission project FRG-HS-3 075-76. 


\section{REFERENCES}

1. Giri M, Giri M, Thapa RJ, Upreti B, Pariyar B. Breast Cancer in Nepal: Current status and future directions. Biomedical Rep. 2018;8:325-9. [uued | Full Text | DOI]

2. Kelly BS, Scanl ON E, Heneghan H, Redmond CE, Healy GM, Mc Dermott E, Heffernan EJ, Prichard R, Mc Nally S. Breast Arterial Calcification on screening mammography can predict significant Coronary Artery Disease in women. Clin Imaging. 2018 May-Jun;49:48-53. [ $\underline{\text { PubMed | Full Text }}$ | DOI]

3. Akinola RA, Ogbera OA et al. Mammograms and breast arterial calcifications: looking beyond breast cancer: a preliminary report. BMC Res Notes 2011;4:207.[Full Text | $\underline{\mathrm{DOI}}]$

4. Moshyedi AC, Puthawala AH, Kurland RJ, O'Leary DH. Breast arterial calcification: Association with coronary artery disease. Work in progress. Radiology. 1995;194:181-3. [PubMed | Full Text | DOI]

5. Ali, E.A., Fouad, H., Razek, N.A. et al. Evaluation of mammography detected breast arterial calcifications as a predictor of coronary cardiac risk. Egypt J Radiol Nucl Med 2019;50:81. [Full Text | DOI]

6. Loberant N, Salamon V, Carmi N, Chernihovsky A. Prevalence and Degree of Breast Arterial Calcifications on Mammography: A Cross-sectional Analysis. J Clin Imaging Sci. 2013;3:36. [ubMed | Full Text | DOI]

7. Mostafavi L, Marfori W, Arellano C, Tognolini A, Speier W, Adibi A, et al. Prevalence of coronary artery disease evaluated by coronary CT angiography in women with mammographically detected breast arterial calcifications. PloS one. 2015 Apr 9;10(4). [PubMed | Full Text | DOI]

8. Kim H, Greenberg JS, Javitt MC. Breast calcifications due to Mönckeberg medial calcific sclerosis. Radiographics. 1999;19(5):1401-3. [uued | Full Text | DOI]
9. Pecchi A, Rossi R, Coppi F, Ligabue G, Modena MG, Romagnoli R. Association of breast arterial calcifications detected by mammography and coronary artery calcifications quantified by multislice CT in a population of post-menopausal women. Radiol Med. 2003;106(4):305-12. [PubMed]

10. Rotter MA, Schnatz PF, Currier AA, O'Sullivan DM. Breast arterial calcifications (BACs) found on screening mammography and their association with cardiovascular disease. Menopause. 2008 Mar-Apr;15(2):276-81. [ㄹuMed | Full Text | DOI]

11. McLenachan, F. Camilleri, M. Smith, D.E. Newby M.C. Williams. Breast arterial calcification on mammography and risk of coronary artery disease: a SCOT-HEART sub-study. Clin Radiol 2019;74(6): 421-8. [Full Text | DOI]

12. Maas AH, van der Schouw YT, Beijerinck D, Deurenberg JJ, Mali WP, van der Graaf Y. Arterial calcifications seen on mammograms: cardiovascular risk factors, pregnancy, and lactation. Radiology. 2006 Jul;240(1):33-8. [ㅁuMed | Full Text | DOI]

13. Reddy J, Son H, Smith SJ, Paultre F, Mosca L. Prevalence of breast arterial calcifications in an ethnically diverse population of women. Ann Epidemiol. 2005 May;15(5):344-50. [PubMed | Full Text | DOI]

14. Margolies LR, Yip R, Hwang E, Oudsema RH, Subramaniam VR, Hecht H, Narula J. Breast Arterial Calcification in the Mammogram Report: The Patient Perspective. Am J Roentgenology 2019;212(1):209-14. [ㅍuMed | Full Text | $\underline{\mathrm{DOI}}]$

15. Fiuza Ferreira EM, Szeinfield J, Faintuch S: Correlation between intramammary arterial calcifications and CAD. Acta Radiol. 2007;14(2):144-50. [PubMed | Full Text | DOI]

\section{The Author(s) 2018.}

This work is licensed under a Creative Commons Attribution 4.0 International License. The images or other third party material in this article are included in the article's Creative Commons license, unless indicated otherwise in the credit line; if the material is not included under the Creative Commons license, users will need to obtain permission from the license holder to reproduce the material. To view a copy of this license, visit http://creativecommons.org/licenses/by/4.0/ 